\title{
A minority within a minority? Identity and sexual health in Black and minority ethnic men who have sex with men in the United Kingdom
}

\author{
Rusi Jaspal PhD \\ Jake Bayley MBChB
}

Rusi Jaspal, PhD, is Pro Vice-Chancellor for Research and Professor of Psychology and Sexual Health at De Montfort University, Leicester, UK (rusi.jaspal@ cantab.net). Jake Bayley, MBChB, is a Consultant Physician in Sexual Health and HIV at Barts NHS Trust, London, UK.

*Corresponding Author: Rusi Jaspal: rusi.jaspal@ cantab.net

\section{Disclosures}

The authors report no real or perceived vested interests related to this article that could be construed as a conflict of interest.

\section{Acknowledgements}

No funding was received.

Key words: sexual health, HIV, identity, ethnic, men who have sex with men, social psychology

Rusi Jaspal PhD, Pro Vice-Chancellor for Research, De Montfort University, Leicester LE1 9BH, United Kingdom. E-mail: rusi.jaspal@cantab.net

Citing this article

Jaspal, R., \& Bayley, J. (in press). A minority within a minority? Identity and sexual health in Black and minority ethnic men who have sex with men in the United Kingdom. Journal of the Association of Nurses in AIDS Care. 


\section{A minority within a minority? Identity and sexual health in Black and minority ethnic men who have sex with men in the United Kingdom}

Identity refers to the individual's self-construal. It is characterized by multiple elements, such as sexuality, ethnicity, and religion, and not all identity elements are simultaneously salient (Jaspal \& Breakwell, 2014). For instance, the same person might selfidentify principally as gay at a Gay Pride March, as Muslim during Ramadan, as Pakistani during a cricket match, and as British when abroad. Social context is key to identity expression. Black and minority ethnic (BME) men who have sex with men (MSM) in the United Kingdom have multiple, often stigmatized, identity elements. Many face intersecting social stressors (e.g., racism, homophobia) that can increase the risk of poor sexual health. Many straddle the boundaries of seemingly incompatible identities, such as ethnicity and sexuality. In this commentary, we present a clinical case study, and relevant theory and research to illustrate the practical importance of identity for effective sexual health care in this diverse population.

\section{Abdul: A Clinical Case Study}

Abdul (a pseudonym) is a 24-year-old man of Bangladeshi origin who initially presented in clinic for post-exposure prophylaxis (PEP) following unprotected anal intercourse with multiple male partners. During the consultation, he reported living with his Muslim family who were unaware of his sexual behavior. Their lack of awareness and his fear of involuntary disclosure of his sexual behavior caused him significant psychological stress. In order to disconnect from this stress, Abdul reported using mephedrone, a recreational drug commonly used by MSM during chemsex. He was referred to local drug services. However, upon attendance, Abdul felt that these services were not culturally appropriate to him and pointed out that, unlike all of the other attendees at the service, he did not self-identify as gay or White British. Abdul disengaged after attending one session.

Abdul presented in clinic 3 months later with symptoms of HIV seroconversion, which was confirmed with a $4^{\text {th }}$ generation HIV test. His drug use had escalated and he was injecting mephedrone and using crystal methamphetamine on a daily basis. He disclosed meeting older gay men who offered him drugs in exchange for sex. Abdul later developed drug-induced psychosis and was admitted to a mental health ward. Abdul reported no prior awareness of public health messages concerning safer sex and indicated that he did not frequent gay bars or read any form of gay literature, because he did not consider himself gay.

\section{Coping with Threatened Identity}

Abdul's case exhibits the importance of identity in relation to sexuality, sexual health knowledge, and engagement with relevant services. Identity Process Theory (Breakwell, 1986; Jaspal, 2018) can shed light on the complex relationship between identity, thinking, and behavior. The theory proposes that identity is constructed through two universal processes: (a) assimilation-accommodation, which refers to the absorption of new information in identity (e.g., "I am gay") and to the adjustment that takes place in order for it to become part of identity (e.g., "I am gay so maybe I cannot be a Muslim"); and (b) evaluation, which confers meaning and value upon the contents of identity (e.g., "Being Muslim is a good thing but being gay is not"). The identity processes function in ways that provide high sufficient levels of identity principles, including continuity, self-esteem, belonging, and identity coherence.

Abdul will understandably refrain from assimilating and accommodating the category "gay" in his identity if this abrogates his self-esteem, continuity, and belonging, and if he views it as being incompatible with his valued Muslim identity. Abdul originated from a 
religious family and, thus, the perceived religious stance on homosexuality may lead him to evaluate it in similarly negative terms. In short, the assimilation-accommodation of the stigmatized category "gay" would not enhance the identity principles.

When identity principles are curtailed, identity is threatened and, in response, the individual will engage in coping strategies (Breakwell, 1986; Jaspal, 2018). These strategies can be either adaptive or maladaptive. Abdul exhibited denial in relation to his sexual identity and, therefore, disengaged from the gay community and from health services aimed at gay men. He views the gay community and gay health services as inconsistent with the identity he has constructed and wishes to project to others. Moreover, he attempts to cope with the stresses of his stigmatized sexual behavior by concealing it, feigning heterosexuality, and engaging in escapist behaviors, such as substance use. Abdul is using strategies that are deflective, escapist, and unlikely to be fruitful in the long term. Moreover, it appears that a combination of identity threat and maladaptive coping strategies, in part, led to his HIV infection.

\section{Psychosocial Casual Factors in Poor Sexual Health}

Due to social stigma related to homosexuality, many BME MSM do not identify as gay, which can limit exposure to sexual health information and inhibit access to relevant sexual health services (Jaspal, Lopes, Jamal, Yap, Paccoud \& Sekhon, 2019). They may prefer not to append the stigmatized label "gay" to their sexual identity, thereby engaging in denial and rejecting sources of relevant sexual health knowledge.

BME MSM face significant social stressors (e.g., discrimination, rejection) as a result of their stigmatized sexual orientation (Jaspal \& Cinnirella, 2010). They may face homophobia from within their ethnic/religious communities, racism from within the gay community, as well as homophobia and racism from the general population. Exposure to multiple social stressors can lead to identity threat and to maladaptive coping strategies (Jaspal, Lopes \& Rehman, 2019), some of which (e.g., drug use, condomless sex) can, in turn, put BME MSM at increased risk of HIV and other sexually transmitted infections (STI). This population is also at higher risk of depressive psychopathology, a known correlate of sexual risk-taking (Jaspal, Lopes \& Rehman, 2019).

This may, in part, explain sexual health inequalities in BME MSM. A case note review of 203 BME MSM revealed that BME MSM were more likely to report unprotected anal sex with casual male partners in the last 3 months and to report more high-risk sexual behavior than other MSM (Soni, Bond, Fox, Grieve \& Sethi, 2008). There were higher rates of bacterial STIs in Black MSM than in other MSM; of all MSM attending genitourinary medicine (GUM) services in England, BME MSM were most likely to be diagnosed with an STI (Mohammed, Furegato \& Hughes, 2016). Moreover, a recent study exhibited a 27\% prevalence of childhood sexual abuse in South Asian MSM, which was associated with sexual risk behavior through the mediating variable of drug use (Jaspal, Lopes, Jamal, Paccoud \& Sekhon, 2017). BME MSM may have decreased access to sexual health services, which may be attributed to limited knowledge of available services, lack of English-language proficiency, and low socioeconomic status (Dhar, Griffiths, Cassell, Sutcliffe \& Brook, 2010). BME MSM may be attempting to cope with social stressors and identity threat by engaging in maladaptive behaviors, such as condomless sex, which may transiently provide feelings of self-esteem, continuity etc, while also increasing the risk of poor sexual health. Knowledge about this empirical research can help clinicians intervene effectively.

\section{Conclusion}

Although MSM generally possess high levels of sexual health knowledge, it must not be assumed that BME MSM are similarly aware of HIV and effective HIV prevention 
approaches (e.g., pre- and post-exposure prophylaxis ) or that they have the same access to information networks as other MSM. It is important to treat, and refer to, patients consistently with their own self-identity categories - for example, although they have sex with men, they may not self-identify as gay. We must acknowledge all identity elements of BME patients, which may limit or constrain engagement with sexual health, and to use culturally appropriate images and language in clinical settings. Furthermore, there may be other unanticipated, but relevant, aspects of patient identity or history. For instance, some BME MSM are heterosexually married due to cultural and religious pressures that can imperil the sexual health of partners who may be unaware of their sexual behavior. Moreover, there is a high prevalence of stressors (childhood sexual abuse, racism) that can increase the risk of poor mental health and sexual health and for which support must pre-emptively be provided. In a context of increased stigma on multiple levels, BME MSM may be more inclined to elect maladaptive, rather than adaptive, coping strategies. It is hoped that we will raise clinical awareness of the unique identity challenges associated with BME MSM patients and, thereby, improve sexual health knowledge and outcomes in this diverse population. 


\section{References}

Dhar, J., Griffiths, C.A., Cassell, J.A., Sutcliffe, L., \& Brook, G.M. (2010). How and why do South Asians attend GUM clinics? Evidence from contrasting GUM clinics across England? Sexually Transmitted Infections, 86, 366-70. doi:10.1136/sti.2009.036004.

Elford, J., Doerner, R., McKeown, E., Nelson, S., Anderson, J., \& Low, N. (2012). HIV infection among ethnic minority and migrant men who have sex with men in Britain. Sexually Transmitted Diseases, 39(9), 678-86. doi: 10.1097/OLQ.0b013e31825c8018.

Jaspal, R. (2018) Enhancing sexual health, self-identity and wellbeing among men who have sex with men: A guide for practitioners. London: Jessica Kingsley Publishers.

Breakwell, G.M. (1986). Coping with threatened identities. London: Metheun. Jaspal, R., \& Breakwell, G.M. (Eds.) (2014). Identity Process Theory: Identity, Social Action and Social Change. Cambridge: Cambridge University Press.

Jaspal, R., \& Cinnirella, M. (2010). Coping with potentially incompatible identities:

Accounts of religious, ethnic and sexual identities from British Pakistani men who identify as Muslim and gay. British Journal of Social Psychology, 49(4), 849-870. doi:

10.1348/014466609X485025.

Jaspal, R., Lopes, B., Jamal, Z., Yap, C., Paccoud, I., \& Sekhon, P. (2019). HIV knowledge, sexual health and behaviour among black and minority ethnic men who have sex with men in the UK: a cross-sectional study. Sexual Health, 16(1), 25-31. doi: 10.1071/SH18032

Jaspal, R., Lopes, B., Jamal, Z., Paccoud, I., \& Sekhon, P. (2017). Sexual abuse and HIV risk behaviour among black and minority ethnic men who have sex with men in the UK. Mental Health, Religion \& Culture, 20(8), 841-53. doi: 10.1080/13674676.2017.1414170 Jaspal, R., Lopes, B., \& Rehman, Z. (2019). A structural equation model for predicting depressive psychopathology in Black, Asian \& Minority Ethnic lesbian, gay \& bisexual people in the UK. Manuscript submitted for publication.

Mohammed, H., Furegato, M., \& Hughes, G. (2016). Inequalities in sexually transmitted infection risk among black and minority ethnic men who have sex with men in England. Sexually Transmitted Infections, 92(Suppl 1), A42. [Abstract] doi: 10.1136/sextrans-2016052718.122

Soni, S., Bond, K., Fox, E., Grieve, A.P., \& Sethi, G. (2008). Black and minority ethnic men who have sex with men: a London genitourinary medicine clinic experience. International Journal of STDs and AIDS, 19(9), 617-9. doi:10.1258/ijsa.2008.008039 